Article - Agriculture, Agribusiness and Biotechnology

\title{
Seasonal Variation of Plant Mineral Nutrition in Fruit Trees
}

André Freire Cruz ${ }^{1, *}$

https://orcid.org/ 0000-0001-9349-2742

Glicia Maria de Almeida ${ }^{2}$

https://orcid.org/0000-0003-1526-8301

Paulo Guilherme Salvador Wadt ${ }^{3}$

https://orcid.org/0000-0002-5429-6308

Marcio de Carvalho Pires ${ }^{4}$

https://orcid.org/0000-0003-2874-8398

\section{Maria Lucrecia Gerosa Ramos ${ }^{4}$}

https://orcid.org/0000-0002-4516-7352

${ }^{1}$ Kyoto Prefectural University, Graduate School of Life and Environmental Sciences, 1-5 Shimogamohangi-cho, Sakyo-ku, Kyoto, Japan; ${ }^{2}$ Kyoto University, Graduate School of Biostudies, Yoshida-Konoe-cho, Sakyo-ku, Kyoto, Japan; ${ }^{3}$ Empresa Brasileira de Pesquisa Agropecuária (EMBRAPA), Centro de Pesquisa Agroflorestal de Rondônia, Cidade Jardim, Porto Velho, RO, Brazil; ${ }^{4}$ Universidade de Brasilia, Faculdade de Agronomia e Veterinária, Brasilia, DF, Brazil.

Received: 2018.07.04; Accepted: 2019.06.16.

*Correspondence: andre@kpu.ac.jp; Tel.: +81-75-7035608

\section{HIGHLIGHTS}

- The currently research determined the seasonal variation of fruit trees mineral status in Japan.

- Six species of fruit trees and several elements (N, P, K, Ca, Mg, Fe, Zn, Cu, Mn, and Mo) were considered.

- Seasonality was found in N, P and K concentration in apple and peach.

- Micronutrient concentration was more uniform over the year.

- Diagnosis Recommendation Integrated System (DRIS) indicated the best nutrient balance for mandarin trees.

Abstract: This research evaluated the monthly variation of plant mineral nutrition in six species of fruit trees over a year. Leaf samples were taken from the fruit trees and nutritional 
status (N, P, K, Ca, Mg, Fe, $\mathrm{Zn}, \mathrm{Cu}, \mathrm{Mn}$, and $\mathrm{Mo}$ ) was determined in the leaves in a month basis from April until November for apple, persimmon and peach. Mandarin mineral nutrition was monitored for one year, and grape and fig from May to November. Using this data, the Diagnosis Recommendation Integrated System (DRIS) was also calculated to evaluate the nutrient balance in the plants. The concentration of $N$ and $P$ had seasonal differences, especially in apple and peach, which reached the peak during the summer. Apple, fig, and grape trees had large ranging on their mineral contents over the year, especially with the $P$ and $\mathrm{K}$ levels reaching the minimum during the harvesting season. However, the seasonal changes in leaf micronutrient concentrations were not uniform and not affected by phenological stage. The DRIS data demonstrated that mandarin had the best nutrient balance compared to others and that $\mathrm{K}$ was the most limiting element among the fruit trees. In summary, the current data suggest the occurrence of a significant seasonality in mineral nutrition in these six fruit trees, especially in temperate ones.

Keywords: Diagnosis Recommendation Integrated System, Fruit Crops, General Plant Nutrition, Nutrient balance.

\section{INTRODUCTION}

Understanding the physiological aspects of tree nutrition includes studies about the seasonal variation of leaf nutrient contents, because the seasonal pattern of nutrient uptake and partitioning is a fundamental portion of fertilizer estimations in fruit orchards, especially in temperate fruits [1]. The harmony between the period and fertilizer application rate within the plant's nutrient demand may lead to maximize yield, and it increases nutrient-use efficiency. In mandarin trees (Citrus reticulata Blanco) the fruiting state had a significant effect on the content of $\mathrm{P}, \mathrm{K}$, and $\mathrm{Mg}$ in both leaves and stems, because these fruits could act as very strong sinks for potassium and phosphorus; therefore, during the harvesting state the $\mathrm{K}$ and $\mathrm{P}$ levels in leaves decreased to deficient levels [2].

The internal nutrient turnover in perennial fruit crops had been well reported, where depending on the growth season there is a specific demanding of a targeted nutrient [3]. The nutrient accumulation is considered as a continuous process during the growing season, and their absorption depend on the nutrients related to that determined growth stage. The fruit can absorb $\mathrm{Ca}$ at early developmental stage, while absorption rates of other macronutrients may increase later during the fruit development [4]. The variations occurring in plant mineral nutrition can be provoked by their metabolism, depending on plant growth stage and their responses to environmental factors [5]. There are many reports which showed $B$ to have a remarkable role in fruit setting [6,7], suggesting that during flowering and fruiting a $B$ deficiency may lead to fruit abscission and reduce yield and quality $[8,9]$.

Commercial growers of fruit, especially of berries, are encouraged to program their fertilization based on recommended rates of nitrogen, considering also other elements resulting from routine soil and leaf nutrient analysis [10].

The monthly variation of plant-nutrient contents has also been examined with guttation fluid samples from Dieffenbachia amonea plants, showing that macroelements decreased in winter, and microelements increased [11]. Furthermore, nutrient levels in blackberry (Rubus L.) leaf vary over the growing season and among their cultivars, so a standardization of sampling time for fertilizer recommendation has been established [12].

Under natural conditions, such as in Mediterranean mountain vegetation, the highly variable leaf-quality characteristics based on $\mathrm{N}$ content among the seasons create a diverse and changing chemical landscape in which the local fauna may choose their preferences for diet, according to plant species, at different times and sites [13].

Although many studies have reported nutrient dynamics in fruit trees during the growing season $[3,4,14]$, the seasonal variation of mineral concentrations in many fruits in the same 
location needs to be compared. A deep analysis of physiological aspects of tree nutrition also depends on the knowledge of the seasonal variation of leaf nutrient contents [15]. These factors are dynamic throughout the year and provide the appropriate recommendation of fertilizer amendment according to plant growth stage. Therefore, the seasonal pattern of nutrient uptake and partitioning is a fundamental component of fertilizer management in fruit orchards. The present study aims to evaluate the seasonality of macronutrients: Nitrogen $(N)$, Phosphorus (P), Potassium (K), Calcium (Ca), Magnesium (Mg), and micronutrients: Cupper $(\mathrm{Cu})$, Iron (Fe), Zinc (Zn), Manganese (Mn) and Molybdenum (Mo) in fruit orchards, including their relationship with plant phenological stages.

\section{MATERIALS AND METHODS}

This study was conducted at Kyoto Prefecture University Experimental Farm, Seika-cho, Kyoto, Japan. The sampling area has these characteristics: Latitud, Longitud (34.772404, 135.765923), Mean Annual Temperature $\left(17^{\circ} \mathrm{C}\right)$, Mean Annual Precipitation (31.7 mm), Relative Humidity (58\%). Leaf samples were collected from six fruit crops: Apple (Malus domestica "Fuji"), Peach (Prunus persica "Benishimizu"), Persimmon (Diospyros kaki "Hiratanenashi"), Fig (Ficus carica "Masui Dalphine"), Mandarin (Citrus unshiu "Satsuma mandarin") and Grape (Vitis vinifera "Fujiminori"), every month during one year. The characteristics of each fruit tree, including their phenological stage and fertilizer application rates, are described in Table 1.

Table 1 Management and growth stage of the fruit trees in the sampled area

\begin{tabular}{ccccccccc}
\hline & & \multicolumn{3}{c}{ Phenological stage } & \multicolumn{3}{c}{ Fertilizer (kg/10a) } \\
\hline Apple & Cultivar & Age & Bloom & Fruit set & Harvesting & $\mathrm{N}$ & $\mathrm{P}$ & $\mathrm{K}$ \\
Peach & Fuji & 15 & June & July & November & 29 & 38 & 10 \\
Persimmon & Benishimizu & 15 & June & July & August & 31 & 31 & 10 \\
Fig & Hiratanenashi & 15 & July & August & October & 15 & 10 & 4 \\
Grape & Fujui Dauphine & 5 & April & May & August & 24 & 12 & 20 \\
Citrus & Satsuma Mandarin & 8 & May & July & December & 20 & 15 & 15 \\
\hline
\end{tabular}

Ten leaf samples from four different trees were taken monthly from the third branch, counting vertically, for the analysis. The fertilization, pesticide application, fruit thinning, and pruning followed the standards in Japanese fruit orchards individually for each type of fruit tree.

The leaves were washed, dried for 72 hours at $60{ }^{\circ} \mathrm{C}$, and then the nutrient concentrations were analyzed as follows. The Kjeldahl method was used to determine the $\mathrm{N}$ concentration in fruit leaves after sulfuric acid digestion. $P$ was measured by colorimetry using a spectrophotometer, and $\mathrm{K}, \mathrm{Mg}, \mathrm{Ca}$ and micronutrients $(\mathrm{Zn}, \mathrm{Mn}, \mathrm{Cu}$, and $\mathrm{Fe}$ ) by atomic absorption spectrophotometry (AAS). All analyses were performed by the Forest Research Society, Federal University of Viçosa, Brazil. The diagnosis recommendation integrated system (DRIS) was estimated to evaluate the nutrient balance for each fruit tree [16-18].

Statistical analyses of data were performed using SPSS software, where mean values and the standard error were measured. 


\section{RESULTS}

The analyses showed that we found that seasons affected $\mathrm{N}$ concentration (Figure 1). The $\mathrm{N}$ values were basically stable over with two peaks in May and September for almost all the fruits analyzed in this study. In peach, the $\mathrm{N}$ concentration had a peak in May and in September. Moreover, persimmon and mandarin had a peak of $\mathrm{N}$ in August and September (Figure 1). The $\mathrm{N}$ concentration decreased in persimmon, fig, and apple from July to August. In peach trees, the values of $\mathrm{N}$ increased in summer, but this crop only reached the peak of $\mathrm{N}$ in September (Figure 1). Similar pattern was found in $\mathrm{P}$ concentration, where the persimmon, grape, and peach were the most variable for this element, while mandarin was the most stable one over the year (Figure 2). Considering all data, it is possible to confirm that the concentration of $\mathrm{N}$ in leaves showed seasonal differences in apple and peach, while $\mathrm{P}$ varied for all fruits, except mandarin.

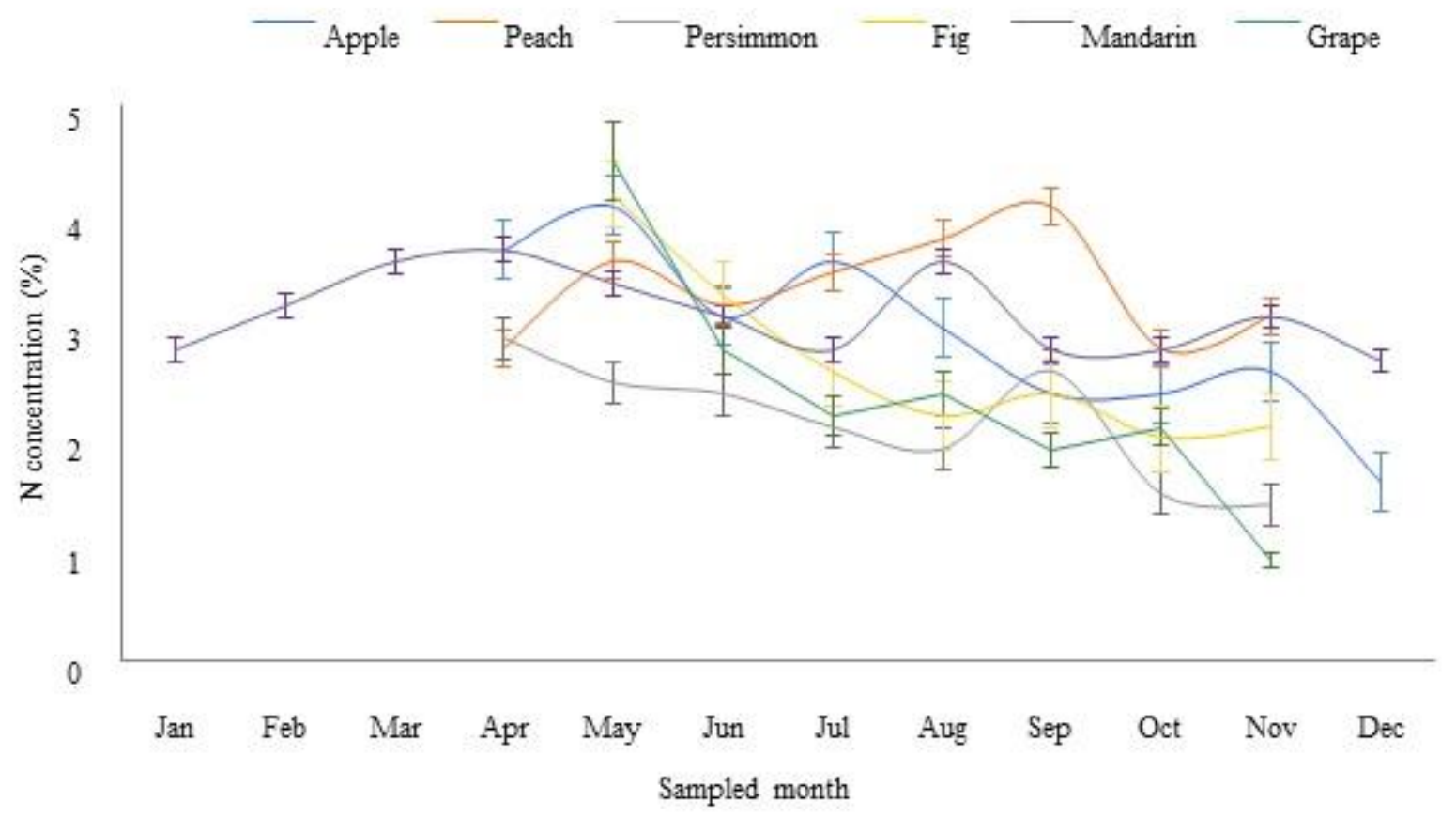

Figure 1. Monthly variation in $\mathrm{N}$ concentration in leaves of six fruit orchards (Apple, Peach, Persimmon, Figs, Grape, Citrus). Bars represent Standard error $(n=4)$. 


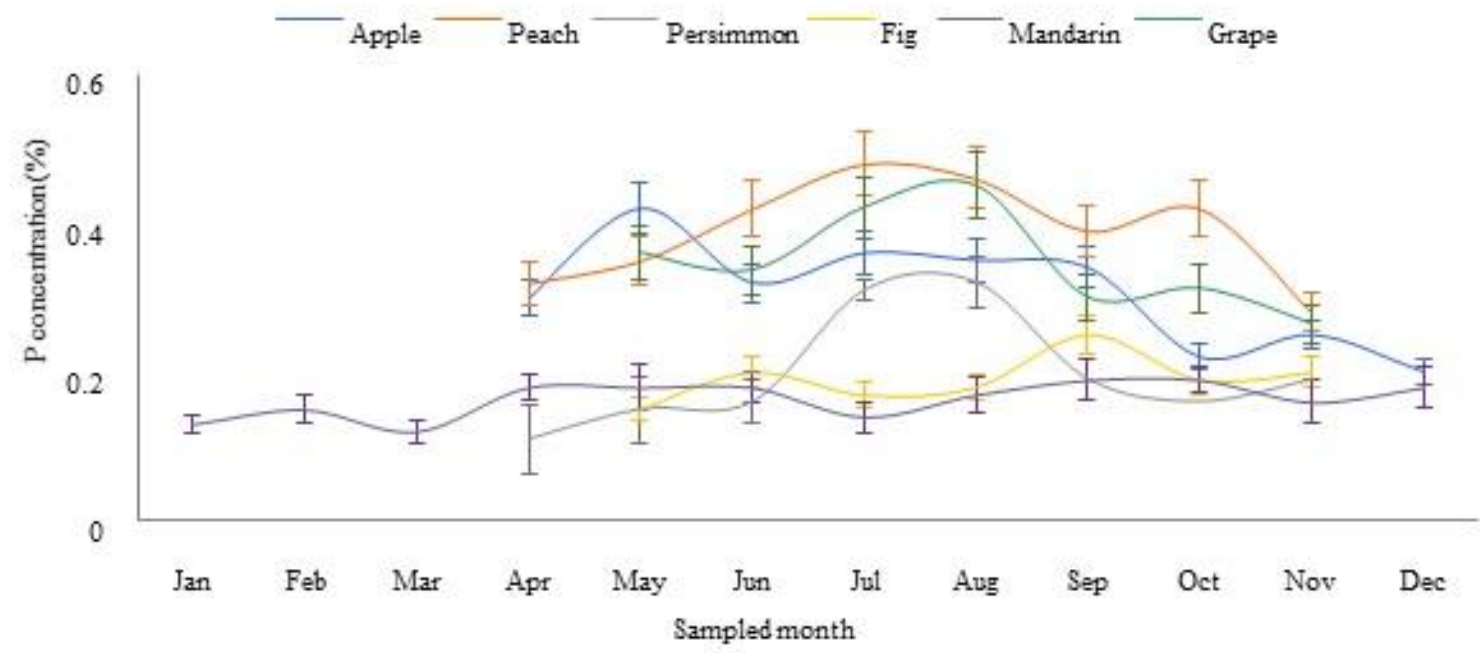

Figure 2. Monthly variation in $P$ concentration in leaves of six fruit orchards (Apple, Peach, Persimmon, Figs, Grape, Citrus). Bars represent Standard error $(n=4)$

Other macro-elements, $\mathrm{K}, \mathrm{Ca}$ and $\mathrm{Mg}$, did not have similar patterns. Their variation over the year depended on the fruit, special attention could be given to $\mathrm{Ca}$ in mandarin and fig, and $\mathrm{Mg}$ only in fig, where there was a higher level compared to others (Suppl. Fig. 1). For the micronutrients, there were not many differences among the plants over the year, except for $\mathrm{Cu}$ and $\mathrm{Zn}$, which were low in mandarin during the spring. Moreover, the $\mathrm{Mn}$ and Mo concentrations were remarkably higher in persimmon and fig, respectively. An increase in the content of the same element was observed throughout the year, except in August, when these fruits start fruit set and harvesting, respectively. Although higher concentrations of this microelement were reported in fig, these concentrations decreased throughout the year (Suppl. Figs 2 and 3).

The DRIS results indicated that mandarin followed by grape had the best NBI, which indicates that these fruit crops were well balanced for nutrients compared to other crops. Peach was most limited by $\mathrm{K}$, and persimmon by $\mathrm{N}$ and $\mathrm{K}$ compared to Figs that were limited by $\mathrm{Zn}$, whereas $\mathrm{Cu}$ was in excess for most fruit crops, except mandarin. However, apple had no limitations in terms of nutrients (Table 2).

Table 2 Diagnosis recommendation integrated system represented by the indexes of each element and nutrient balance (NBI) for each fruit tree over the year

\begin{tabular}{lccccccccccc}
\hline & $\mathrm{N}$ & $\mathrm{P}$ & $\mathrm{K}$ & $\mathrm{Ca}$ & $\mathrm{Mg}$ & $\mathrm{Cu}$ & $\mathrm{Fe}$ & $\mathrm{Zn}$ & $\mathrm{Mn}$ & $\mathrm{Mb}$ & $\mathrm{NBI}$ \\
\hline Apple & 0.032 & 0.125 & 0.115 & 0.004 & 0.024 & 0.358 & 0.016 & 0.279 & 0.198 & 0.292 & 0.160 \\
Peach & -0.038 & 0.092 & -0.251 & -0.022 & -0.058 & 0.289 & -0.126 & 0.248 & 0.278 & 0.278 & 0.187 \\
Persimmon & -0.279 & 0.137 & -0.280 & 0.211 & -0.017 & 0.185 & -0.112 & 0.386 & 0.156 & 0.233 & 0.222 \\
Figs & 0.062 & 0.171 & -0.105 & 0.136 & 0.019 & 0.525 & -0.180 & -0.136 & -0.022 & 0.059 & 0.157 \\
Grape & 0.067 & 0.181 & -0.097 & -0.077 & -0.181 & 0.227 & -0.080 & 0.029 & 0.125 & 0.319 & 0.154 \\
Mandarin & 0.088 & -0.050 & 0.069 & 0.145 & 0.042 & -0.006 & 0.015 & 0.201 & 0.054 & 0.009 & 0.075 \\
\hline
\end{tabular}

\section{DISCUSSION}


The results of this study reveal that the studied fruit trees differed in their nutrient composition between species and times. As seasonality also has genetic components [19] that depend on the plant species, we analyzed data from six different species. The monthly variation in the nutrient concentration for these fruit trees suggests a significant effect of this trait. The highest difference was found between spring and summer for the temperate fruit trees, whereas with the mandarin such variations were not so significant. Seasonal chemical changes are usually a well-known cause of variation within species [13], especially nitrogen concentration and tannins. Other chemical compounds such as the carbohydrate storage was also reported as a major difference among seasons within the same species [20]. The application of balanced amounts of a high limiting nutrient would induce a reasonable yield improving while maximizing the nutrient using efficiency [21].

Soil health, which includes $P$ concentration and the phenological stage of the fruit tree, can affect plant mineral nutrition [14]. In tropical fruits, the $\mathrm{N}$ remobilization is very high from older parts to new ones and from absorption from the soil, suggesting that the fertilizer management in these trees might be linked to maintain the reserves and reduce the losses [3]. The current research detected variation by season; however, the site and cultivars of the same fruit species should be considered too.

It is notable that the excess of $P$ in the soil might induce the inhibition of other nutrients uptake [22]. Therefore, the $P$ excess in leaves of some fruit crops, for example, persimmon, may be explained by environmental factors, phenological stages, and soil properties. In the current study, the nutrient status among the trees was characterized by a deficiency of $\mathrm{N}$ and $\mathrm{K}$ in peach and persimmon, with an excess of $\mathrm{Zn}$ and $\mathrm{Mb}$ for most of the trees. Generally, soils with low organic matter that receive high dosages of $P$ may exhibit an excess of $Z n$, as this element is proportional to $\mathrm{P}$ in soils. In addition, Fe availability could be reduced in a season of heavy rainfall [23], so peach, persimmon, fig and grape might be unable to uptake Fe during this strong rain. However, it might not affect the yield itself, because other nutrients also influence the final production and fruit quality.

Leaf $\mathrm{N}$ and $\mathrm{S}$ levels declined throughout the floricane-fruiting season in blackberry [12, 24]. This decline might be due to dilution, and/or translocation to fruit that is relatively high in $\mathrm{N}$. In addition, the leaf $\mathrm{K}$ may decrease during fruit development in caneberries [10, 25].

The leaf $P$ contents also may decrease after fruit set in mandarin [2]. The current study showed some stability of $\mathrm{K}$ content in leaves throughout the year, except for apple and persimmon, but in most of the fruit trees, a decrease occurred after harvesting. Corroborating these data, other authors also found the same decrease in olive and pistachio [26]. The dynamics of $\mathrm{K}$ indicate that it is a very mobile macronutrient [6]. Therefore, the supply of $\mathrm{K}$ for fruit trees at the time of fruit set is crucial in reaching high fruit quality, a very important requirement in the fruit market in Japan, where appearance is much prized.

The amount of $\mathrm{Mg}$, in leaves was significantly affected by the phenological stage, especially during the flowering and fruit set. The patterns of seasonal changes in these elements were corroborated in previous studies carried out with mandarin and pistachio [27]. The concentrations of $\mathrm{Mg}$ in fruit trees could be linked to their functions, such as numerous enzymatic reactions involving energy provision [6]. In the present study, leaf $\mathrm{Fe}$ and $\mathrm{Mn}$ contents were not affected by seasonality, except in persimmon, with a slight decrease during the summer. This phenomenon may result because the fruit does not act as a sink for these elements.

\section{CONCLUSIONS}

This study reported that in five temperate (Apple, Peach, Persimmon, Fig and Grape) and one evergreen (Satsuma mandarin) fruit trees there was a significant seasonal variation in their nutrients, especially the $\mathrm{N}$ and $\mathrm{P}$. The concentration of $\mathrm{P}$ and $\mathrm{K}$ were found low during the fruit formation, where the fruit could be sinks for $\mathrm{P}$ and $\mathrm{K}$, which might be involved in 
flowering. Thus, fertilizer management which specially includes these two elements is likely to affect yield and fruit quality. The mandarin trees showed the best nutrient balance, whereas the Persimmon the most unbalanced in terms of mineral nutrition. The $\mathrm{N}$ was the most deficient nutrient and the Mb was in excess.

Acknowledgements:The authors are grateful to all staff and faculty members at the Kyoto Prefectural University Experimental Farm for allowing them to take samples and for providing the facilities for analysis.

\section{REFERENCES}

1. Nachtigall, G.R.; Dechen, A.R. Seasonality of nutrients in leaves and fruits of apple trees. Sci Agric 2006, 63,493-501.

2. Mirsoleimani, A.; Shahsavar, A-R; Kholdebarin, B. Seasonal changes of mineral nutrient concentrations of leaves and stems of "Kinnow"mandarin trees in relation to alternate bearing. Int J fruit Sci 2014, 14, 117-132.

3. Kotur, S.C.; Murthy, S.V.K. Nutrient dynamics of annual growth-flush in mango (Mangifera indica L.). J Hortic Sci 2016, 5, 75-77.

4. $\quad$ Casero, T.; Torres, E.; Alegre, S.; Recasens, I. Macronutrient accumulation dynamics in apple fruits. J Plant Nutr 2017, 40, 2468-2476.

5. Hartley, S.E.; Jones, C.G. Plant chemistry and herbivory, or why the world is green. Wiley Online Library, 1997.

6. Marschner, H. Marschner's mineral nutrition of higher plants. Academic press, 2011.

7. Wang, H.; Wang, Y.; Du, C.; Xu, F.; Yang, Y. Effects of boron and calcium supply on calcium fractionation in plants and suspension cells of rape cultivars with different boron efficiency. J Plant Nutr 2003, 26, 789-806.

8. Lieten, P. Boron deficiency of strawberries grown in substrate culture. In: IV International Strawberry Symposium 567, 2000, pp 451-454.

9. Xiao, J.X.; Yan, X.; Peng, S.A.; Fang, Y.W. Seasonal changes of mineral nutrients in fruit and leaves of "Newhall"and "Skagg"s Bonanza'navel oranges. J Plant Nutr 2007, 30, 671-690.

10. Bolda, M.; Cahn, M.D.; Gaskell, M.; Mitcham, E.J. Fresh market caneberry production manual. UCANR Publications, 2012.

11. Pilanali, N. Investigation of monthly variation in some plant-nutrient contents of guttation fluid samples taken from Dieffenbachia plants. J Plant Nutr 2005, 28, 1375-1382.

12. Strik, B.C. Seasonal variation in mineral nutrient content of primocane-fruiting blackberry leaves. HortScience 2015, 50, 540-545.

13. Baraza, E.; Hodar, J.A.; Zamora, R. Species, site and seasonal variation in leafchemistry diversity of woody Mediterranean plants. Rev Écol (Terre Vie), 2009, 64, 135-144.

14. Brunetto, G.; Melo, G.W.B.; Toselli, M.; Quartieri, M.; Tagliavini, M. The role of mineral nutrition on yields and fruit quality in grapevine, pear and apple. Rev Bras Frutic 2015, 37, 1089-1104.

15. Mir, M.; Sharma, S.D.; Kumar, P. Nutrient Dynamics: Effect on cropping behavior, nutrient profile and quality attributes of Pomegranate (Punica granatum L.) under rainfed agroclimatic conditions. J Plant Nutr 2015, 38, 83-95.

16. Wadt, P.G.S.; Novais, R.F.; Alvarez-Venegas, V.H.; Braganca, S.M. "DRIS" application alternatives for the coffee (Coffea canephora Pierre) crop. Sci Agric 1999, 56, 83-92.

17. Wadt, P.G.S.; Silva, D.J.; Maia, C.E., Tomé Júnior, J.B.; Pinto, P.A.C.; Machado, P.L.O.A. Modelling of functions in calculating DRIS indices. Pesq Agrop Bras 2007, 42, 5764.

18. Matos, G.S.B.; Fernandes, A.R.; Wadt, P.G.S.; Franzini, V.I.; Souza, E.M.C.; Ramos, H.M.N. Dris calculation methods for evaluating the nutritional status of oil palm in the Eastern 
Amazon. J Plant Nutr 2018, 41 (10), 1240-1251.

19. Muñoz-Fambuena, N.; Mesejo, C.; Carmen González-Mas M.; Primo-Millo, E.; Agusti, M.; Iglesias, D.J. Fruit regulates seasonal expression of flowering genes in alternate-bearing "Moncada" mandarin. Ann Bot 2011, 108 (3), 511-519.

20. Liu, W.; Su, J.; Li S, Lang, X.; Huang, X. Non-structural carbohydrates regulated by season and species in the subtropical monsoon broad-leaved evergreen forest of Yunnan Province, China. Sci Rep 2018, 8(1), 1083.

21. Roy, R.N.; Finck, A.; Blair, G.J.; Tandon, H.L.S. Plant nutrition for food security. A Guid Integr Nutr Manag FAO Fertil Plant Nutr Bull 2006, 16, 368.

22. Rietra, R.P.J.J; Heinen, M.; Dimkpa, C.O; Bindraban, P.S. Effects of Nutrient Antagonism and Synergism on Yield and Fertilizer Use Efficiency. Commun Soil Sci Plant Anal 2017 48, 1895-1920.

23. Long, X.; Ji, J.; Balsam, W. Rainfall - dependent transformations of iron oxides in a tropical saprolite transect of Hainan Island, South China: Spectral and magnetic measurements. J Geophys Res Earth Surf 2011, 116 (F3).

24. Mohadjer, P.; Strik, B.C.; Zebarth, B.J.; Righetti, T.L. Nitrogen uptake, partitioning and remobilization in "Kotata"blackberry in alternate-year production. J Hortic Sci Biotechnol 2001, 76, 700-708.

25. Hart, J.M.; Strik, B.; White, L.; Yang, W. Nutrient management for blueberries in Oregon. Corvallis, Or.: Extension Service, Oregon State University, 2006.

26. Ulger, S., Sonmez, S., Karkacier, M.; Ertoy, N.; Akdesir, O.; Aksu, M. Determination of endogenous hormones, sugars and mineral nutrition levels during the induction, initiation and differentiation stage and their effects on flower formation in olive. Plant Growth Regul 2004, 42, 89-95.

27. Baninasab, B.; Rahemi, M.; Shariatmadari, H. Seasonal changes in mineral content of different organs in the alternate bearing of pistachio trees. Commun Soil Sci Plant Anal 2007 38, 241-258.

(C) (5) \&) 2018 by the authors. Submitted for possible open access publication EY NC BY NC) license (https://creativecommons.org/licenses/by-nc/4.0/). 